\title{
Simulation of Optimal Decision-Making Under the Impacts of Climate Change
}

\author{
Møller, Lea Ravnkilde; Drews, Martin; Larsen, Morten Andreas Dahl
}

Published in:

Environmental Management

Link to article, DOI:

10.1007/s00267-017-0852-1

Publication date:

2017

Document Version

Peer reviewed version

Link back to DTU Orbit

Citation (APA):

Møller, L. R., Drews, M., \& Larsen, M. A. D. (2017). Simulation of Optimal Decision-Making Under the Impacts of Climate Change. Environmental Management, 60(1), 104-117. https://doi.org/10.1007/s00267-017-0852-1

\section{General rights}

Copyright and moral rights for the publications made accessible in the public portal are retained by the authors and/or other copyright owners and it is a condition of accessing publications that users recognise and abide by the legal requirements associated with these rights.

- Users may download and print one copy of any publication from the public portal for the purpose of private study or research.

- You may not further distribute the material or use it for any profit-making activity or commercial gain

- You may freely distribute the URL identifying the publication in the public portal 


\title{
Simulation of Optimal Decision-Making under the Impacts of Climate Change
}

Authors: Lea Ravnkilde Møller ${ }^{1 *}$, Martin Drews ${ }^{2}$, and Morten Andreas Dahl Larsen $^{2}$

${ }^{1}$ UNEP DTU Partnership, DTU Management Engineering, Technical University of Denmark, Marmorvej 51, DK-2100 Copenhagen, Denmark

${ }^{2}$ Department of Systems Analysis, DTU Management Engineering, Technical University of Denmark, Produktionstorvet, building 426, DK-2800 Kgs. Lyngby, Denmark

${ }^{*}$ Corresponding author: mard@dtu.dk

DOI: $10.1007 / \mathrm{s} 00267-017-0852-1$

Key words: Bayesian updating, Monte Carlo simulation, climate change, adaptation, agriculture, uncertainty

\begin{abstract}
Climate change causes transformations to the conditions of existing agricultural practices appointing farmers to continuously evaluate their agricultural strategies, e.g. towards optimizing revenue. In this light, this paper presents a framework for applying Bayesian updating to simulate decision-making, reaction patterns and updating of beliefs among farmers in a developing country, when faced with the complexity of adapting agricultural systems to climate change. We apply the approach to a case study from Ghana, where farmers seek to decide on the most profitable of three agricultural systems (dryland crops, irrigated crops and livestock) by a continuous updating of beliefs relative to realised trajectories of climate (change), represented by projections of temperature and precipitation. The climate data is based on combinations of output from three global/regional climate model combinations and two future scenarios (RCP4.5 and RCP8.5) representing moderate and unsubstantial greenhouse gas reduction policies respectively.

The results indicate that the climate scenario (input) holds a significant influence on the development of beliefs, net revenues and thereby optimal farming practices. Further, despite uncertainties in the underlying net revenue functions, the study shows that when the beliefs of the farmer
\end{abstract}


(decision-maker) opposes the development of the realised climate, the Bayesian methodology allows for simulating an adjustment of such beliefs, when improved information becomes available. The framework can therefore help facilitating the optimal choice between agricultural systems considering the influence of climate change.

\section{Introduction}

The UN Intergovernmental Panel on Climate Change (IPCC) states that the climate system is warming and that anthropogenic drivers are extremely likely to have been the dominant cause of the observed warming since the mid-20th (IPCC 2013). The evidence of climate change is unequivocal, and it is likely that further warming will increase the "likelihood of severe, pervasive and irreversible impacts for people and ecosystems" (IPCC 2014). Thus, climate change represents a serious global risk, which demands an urgent global response (e.g. Stern 2006). Arguably, climate change will have the greatest effect on the poorest and most vulnerable developing countries and population groups (Das Gupta 2014, IPCC 2014). Hence, many parts of the developing world are likely to experience climate-induced declines in agricultural output, poorer health conditions, modifications of rainfall patterns, and more frequent natural disasters e.g. floods, droughts or storms. Consequently, some areas will be rendered increasingly inhabitable, and poverty reduction and economic growth will be severely hindered.

One characteristic of the changing climate is that projections of climate change, even for short time horizons, are associated with a high degree of uncertainty (e.g. Refsgaard et al. 2013), stemming from different sources such as model uncertainty (e.g. Hawkins and Sutton 2011, Larsen et al. 2013), scenario uncertainty (e.g. Yip et al. 2015), natural variations (e.g. Deser et al. 2012), and incomplete knowledge of the climate system (e.g. Oreskes et al. 1994). This aggregated uncertainty, and the best responses here to, is not easily identified through observed time series of the past climate and its systemic impacts, nor through more dynamic approaches, including experiments of trial-and-error. Rather, we are likely to learn about the actual realization of climate change only as time passes, in particular at the detailed level. This is true not only for changes in, e.g. precipitation patterns or the severity of droughts, but also for drivers of these changes (e.g. greenhouses gas $\{\mathrm{GHG}\}$ emissions), and the uncertainties of these factors. Likewise, the potential impacts of climate change are associated with a high uncertainty, such as the resulting agricultural yields, which are conditioned not only on climate but also on the installed adaptive measures, management practices and technologies, etc. Conversely, traditional economic approaches towards characterising such uncertainty tend to rely 
almost entirely on past experiences, e.g. the real option literature, where the value gained from additional information before making an irreversible investment is estimated (Arrow and Fischer 1974; Simal and Ortega 2011).

Risk and uncertainty are central concepts for decision-making on both mitigation and adaptation to climate change. Where 'risk' generally refers to cases where the probability of outcomes can be ascertained through wellestablished theories and the availability of suitable data, 'uncertainty' as mentioned above refers to situations where appropriate data may be fragmentary or unavailable (Halsnæs et al. 2007). Climate change scenarios used by e.g. the IPCC (2014) in general cannot be assigned with accurate numerical probabilities. Instead conclusions are expressed in terms like "very likely", which may again be transferred to an approx. numerical value (e.g. "> 90\% probability"). Budescu, Broomell and Por (2009) have criticised the IPCC for not explicitly considering the numerical probability of climate change, and they conclude that the consequence of this lack is that different people will interpret the probability terms differently, regardless of the international guidelines. This in turn may skew decisions and introduce significant ambiguity, since risk-based methods are widely used to analyse decision-making in connection with climate change (Vardas and Xepapadeas 2010; Klibanoff, Marinacci and Mukerji 2003). As a result the decisionmaker's capabilities and personal bias can play a significant role i.e. in the interpretation of the occurrence that are most likely to happen in the future (or in the decision-makers' expectation of the future) and are often compounded by the level of individual 'risk aversion'.

In the following we investigate jointly the abovementioned aspects of risk, uncertainty and the potential role played by a farmer's personal 'beliefs' in a quantitative manner. In particular, we address the uncertainty related to observations and climate change projections on different time scales and leverage this by adjoined estimates of economic potential and risk related to (adaptation of) different agricultural systems as well as the effect of an initial bias introduced by a farmer's beliefs. To do so, we use the methodology of Yousefpour et al. $(2014,2015)$ to simulate an adaptive decision-making framework, addressing the abovementioned complexity of making 'optimal' decisions for the future under the influence of climate change. This includes the difficult issue of timing, that is, the process of determining when a decision-maker (here: the farmer) should shift focus from one (agricultural) system to another. It is assumed that the decisionmaker holds an initial set of subjective beliefs towards the likelihood of various climate realizations that for completeness add up to one. As time passes, an adaptive decision-maker will carefully observe the development of the climate and based hereon, make rational decisions on how to optimize 
revenues. To represent this process Yousefpour et al. (2014, 2015) introduced a Bayesian methodology for updating decision-makers' beliefs towards different climate realizations based on observations. The framework makes it possible to simulate the trajectory of learning and reaction patterns among decision-makers in examples where the situation does not develop as expected or predicted. Alternative approaches in this regard includes recent work by Martin et al. (2011), McDonald-Madden et al. (2011) and Chhetri et al. (2010), who for example have explored stochastic dynamic programming as a tool for modelling adaptive decisionmaking under climate change.

The framework for Bayesian updating we apply matches the process of choosing between agricultural systems as climate change adaptation, and stipulates the advantages of proactive (ex ante - avoid learning by shock [Tschakert and Dietrich 2010]) over reactive adaptation (ex post - learning by shock) to climate change. Several authors find that proactive adaptation activities can provide significant welfare gains and build resilience to climate change at household level (Boko et al. 2007). Similarly, reactive adaptation can in the long run contribute with proactive initiatives by adding to the pool of knowledge on how to deal with climate change (Lecocq and Shalizi 2007). Fankhauser, Smith and Tol (1999) on the other hand highlight that the line between proactive and reactive adaptation can be blurred when working within a dynamic setting. Thus in this study we have also implemented the irreversible decisions that must be made to create more permanent adaptation strategies, as opposed to temporary coping strategies and autonomous adaptation initiatives.

To illustrate the methodological aspects of decision-making we use the example of a representative farmer's choice of agricultural system in Ghana as adaptation to climate change, e.g. simulating reaction patterns among farmers in response to observations of the 'real' climate development. As a result, the farmer may opt to change the choice of agricultural system, as a response to observations, and confidence in climate projections is built by experiencing the realized changes over time. In principle, this makes it possible to determine which future choices are optimal, when the true climate trajectory is revealed over time, though this may be clouded by inherent sources of uncertainty related to e.g. the internal variability of the climate system and climate models.

The example of a representative farmer represents a hypothetical decisionmaking problem, and indicates how every day (potentially irreversible) decisions can be biased by a wide range of factors. While climate change impacts in the agricultural sector may involve adjustments from season to season for some crops (autonomous adaptation), some changes will require 
adjustments to the production system as such, which may not be easily reversible in the short run. Technically, it may be possible, but the costs would be too high for the farmer in the short run, and any changes to agricultural systems represent medium- to long-term strategies, at least implicitly. This may of course result in new pressures on common land for grassing and on water for irrigation, or it may be seen as an on-going process of choosing which land to allocate to the different systems. Hence, in real life, farmers may use several agricultural systems on different pieces of land.

\section{Adaptation to Climate Change in African Agriculture}

The potential impacts of climate change on African agriculture are expected to be severe and lead to significant losses in the aggregated production without the implementation of effective adaptation (Challinor et al. 2014). The projected warming combined with e.g. reduced and/or highly variable future rainfall patterns is therefore expected to have large effects on select crop types. At the same time the adoption of modern technologies in many parts of Africa, including Ghana, is low, and the local economies highly dependent on agriculture. Several studies suggest that suitable adaptation measures may reduce these negative impacts of climate change on agriculture and crop yields (Antwi-Agyei et al. 2012; Antwi-Agyei, Stringer and Dougill 2014; Antwi-Agyei, Dougill and Stringer 2015; Benhin 2008; Boko et al. 2007). For example, Boko et al. (2007) argue that proactive adaptation may result in welfare gains and resilience to climate change on the household level. On the other hand, Benhin (2008) argues that without adaptation, the net crop revenues concentrated in South Africa are likely to fall by as much as $90 \%$ over the course of the 21 st century, and that climate change will have the greatest impact on small-scale farmers.

In case studies from north-eastern Ghana, Antwi-Agyei, Dougill and Stringer (2015) identify a poor development of the necessary infrastructure, prevention of market access and missing access to new drought-tolerant species as some of the key barriers towards climate change adaptation in the region. Their studies further show how the barriers can be as simple as a lack of information on adaptation options and of understanding the need for implementing adaptation initiatives. Hence, not all farmers are aware of climate change and the consequences they can have in the longer term. Antwi-Agyei, Dougill and Stringer (2015) conclude that it is critically important to address these barriers to be able to implement climate change adaptation in the agricultural sector. In this context, Boko et al. (2007) along with Antwi-Agyei, Stringer and Dougill (2014) and Antwi-Agyei, Dougill and Stringer (2015) all propose that proactive approaches enhance the adaptation to climate change. Importantly, they also find that farmers are 
willing to implement on-farm adaptation strategies and that their decisions highly depend on observations of present climatic conditions. Hence, Boko et al. (2007) show that farmers in Africa tend to select crops that are adapted to the current climate in their region, and that they tend to shift towards more heat-tolerant crops, as the weather becomes warmer. Likewise, an increase or decrease in precipitation makes farmers shift towards more moist-tolerant or drought-tolerant species, assuming they are available to the individual farmer.

Evidently, the key to overcoming some of the barriers mentioned may be to find a balance between flexibility (e.g. the opportunity of switching to different types of crops), reducing the vulnerability of the agricultural systems and optimizing the returns obtained by individual farmers. Different crops require different conditions to produce the highest returns. Switching from one agricultural system to another may involve cost and time lags before new crops yield a profit, causing some decisions to be effectively irreversible, and some crops may perform more inconsistently than other crops with regard to revenues in the face of climate change.

How to address the trade-offs between these different aspects in an evolving climate is the focus of this paper. In the paper, we discuss key issues related to adaptation decision-making using a probabilistic framework that simulates how to make an 'optimal' choice of agricultural system that may or may not change dynamically over time, as information about the future climate trajectory is revealed, and compounded by the initial and shifting expectations of the farmer. Combined, this yields a numerical simulation of the decision-makers' learning trajectory, in this example a farmer's, to allow us to investigate explicitly the roles of learning and user preferences in adaptation decision-making, which may be critical in terms of designing effective adaptation strategies, but which are often ignored by integrated decision-support systems.

\section{Methods and Data}

To simulate how management decisions may change when new and potentially improved information becomes available we employ the methodology of Yousefpour et al. (2014, 2015). In their original formulation, Yousefpour et al. (2014, 2015) introduce a Bayesian methodology for numerically modelling how the 'beliefs' of local forest managers are updated as simulated observations are drawn from the 'true' climate trajectory (initially unknown to the decision-maker) and becomes available over time. The climate development is represented by output of mean- and minimum temperatures and precipitation from three climate model projections. Based here on, they discuss best management strategies at three different points 
in time, whether their behaviour is 'active-adaptive' or not, as well as local conditions and forest characteristics such as the performance of select tree species as defined by a forest landscape model, available management options and schemes and ownership types.

In this study, we adopt a different approach to better reflect the reality of a Ghanaian farmer's choice of agricultural system under climate change. The farmer's beliefs are here updated based on simulated observations of annual mean temperature and precipitation. Since crops are annual and thus easier to replace we consider short five-year time slices as the baseline for decisions on new management strategies, which we simply define as a choice of 'dryland farming' (i.e. rain fed crops), 'irrigated farming' or 'livestock' as in Kurukulasuriya et al. (2006). For this aim, we initially carry out a detailed analysis of state-of-the-art regional climate model projections for Ghana to properly account for interannual variations of temperature and precipitation in our choice of climate realizations, which may have a profound effect on the agricultural performance and related adaptation decisions on annual-to-decadal time scales. Finally, we use the net revenue per farm for each type of agricultural system, calculated using the Ricardian method of Kurukulasuriya et al. (2006), as the sole determinant of optimal decisions on adaptation. In line with this model, we do not explicitly consider, e.g. crop characteristics as part of our decision-space, and neither local soil types, water resources availability, etc. as these are more or less implicit in the model by Kurukulasuriya et al. (2006).

\section{Updating Beliefs Using Bayesian Analysis}

As in Yousefpour et al. (2015), we simulate how a farmer's beliefs concerning three different climate model projections, selected from a larger ensemble (see below), would change in the period from 2015 to 2085 as new annual observations of the actual climate development emerge. Let $W_{i t}$ indicate the farmer's belief that a particular climate projection (i) from a selection of ( $n=$ 3 ) ensemble members will be realized in the year $t$, and that the sum of beliefs is normalized to one as if they were probabilities (Equation 1):

$\sum_{i=1}^{n} w_{i t}=1, w_{i t} \geq 0$ for all $i, t$.

Thus, if a farmer truly believes in a specific climate projection $j$, the belief towards this realization is given by $w_{j t}=1$ while $w_{i t}=0$ for $i \neq j$. We assign the farmer's initial beliefs $w_{\text {io }}$ to the year 2015. 
We use Bayes' theorem (Bayes and Price 1763) iteratively to update the farmer's beliefs every year from 2016-2085. Assuming $x_{t}{ }^{0}$ to be an estimate (observation) of the state of the climate (annual mean temperature, annual mean precipitation) randomly drawn from a multivariate normal distribution centred around the 'true' (realized) climate development (here: as simulated by a climate model), then the updated beliefs (probabilities) at time $t+1$ related to the situation at time $t$ for each of the $n=3$ different climate model projections are given by (Equation 2):

$$
w_{i, t+1}\left(x_{t}^{o}\right)=\operatorname{Pr}\left(\operatorname{model}_{i} \mid x_{t}^{o}\right)=\frac{\operatorname{Pr}\left(x_{t}^{o} \mid \operatorname{model}_{i}\right) \operatorname{Pr}\left(\operatorname{model}_{i}, t\right)}{\sum_{i=1}^{n} \operatorname{Pr}\left(x_{t}^{o} \mid \operatorname{model}_{i}\right) \operatorname{Pr}\left(\operatorname{model}_{i}, t\right)}
$$

where the updated belief $w_{i, t+1}=\operatorname{Pr}\left(\operatorname{model}_{i} \mid x_{t}^{0}\right)$ is the probability of climate projection $i$ representing the true realization of climate change given the observation $x_{t}^{0}$ at time $t, \operatorname{Pr}\left(x_{t}^{0} \mid\right.$ model $\left._{i}\right)$ is the probability that the observation $x_{t}^{0}$ is drawn from the distribution centred around climate projection $i$ at time $t$, and $\operatorname{Pr}\left(\operatorname{model}_{i}, t\right)$ is the probability of model representing the real climate development at time $t$. Using Equation 2 we can update the farmer's beliefs in each of the alternative climate projections, provided we know what the real climate development will be. In the present analysis, we select each of the three different climate projections in turn to represent the real climate, e.g. a 'perfect' model approach. Realistically, none of the three climate projections however will mimic exactly the real climate and hence one could have chosen an alternative approach, where e.g. a fourth projection would represent the actual climate, introducing the further complication of a climate modelling bias (see the discussion below).

For simplicity, we assume that the simulated observations of annual mean temperature and annual mean precipitation are drawn from a multivariate normal distribution centred on the real climate realization (Equation 3),

$\lambda_{x_{t}^{o} \sim N}\left(\bar{\lambda}_{x_{t}^{0}}(\right.$ temp, prec $\left.), \operatorname{Cov}\left(\lambda^{\text {temp }}, \lambda^{\text {prec }}\right)\right)$

where $\lambda^{\text {temp }}$ and $\lambda^{\text {prec }}$ in Equation 3 are calculated from running 30-year time slices of projected annual temperature and precipitation produced by a climate model centred on the consecutive observation points (2020, $2025, \ldots, 2085)$ used for the management analysis discussed below, and 
$\operatorname{Cov}(. .$.$) is the symmetric and positive definite covariance matrix calculated$ from the annual mean temperature and precipitation series. Using running time slices rather than estimating the covariance matrix from the full time series as done by Yousefpour et al. (2015) allows for the simulated climate to exhibit natural variations consistent with the climate model projections and adequate for considering five-year periods. Hence, in the real climate system multi-year to multi-decadal variations occur naturally (e.g. extended periods of more or less precipitation) which may partly or wholly overlap any five-year period, as used in this study to represent the aggregated knowledge of the farmer used (at each observation point) to decide a potential change in management practices. Subsequently, the belief update, which is based on new observations of the present climate conditions, is likely to be influenced by such natural climate variations. Using a 30-year time slice as the basis for estimating the interannual covariance is consistent with current practices amongst climate and weather modellers, where 30-year averages are typically considered as the base for calculating e.g. climate normal or changes to climate variables in a future climate (assuming approximate stationarity).

The probability distribution of the multivariate normal distribution for annual mean temperature and precipitation is defined by Equation 4 with $k=2$ and the rest of the terms as defined above.

$$
\begin{aligned}
& \operatorname{Pr}\left(x_{t}^{0} \mid \operatorname{model}_{i}\right)=\frac{1}{(2 \pi)^{\frac{k}{2}}\left(\operatorname{Cov}\left(\lambda^{\text {temp }}, \lambda^{\text {prec }}\right)\right)^{1 / 2}} \\
& \exp \left(-1 / 2\left[\left(\lambda_{x_{t}^{0}}-\bar{\lambda}_{x_{t}^{0}}\right) \operatorname{Cov}\left(\lambda^{\text {temp }}, \lambda^{\text {prec }}\right)\left(\lambda_{x_{t}^{0}}-\bar{\lambda}_{x_{t}^{0}}\right)\right]\right)
\end{aligned}
$$

In our simulations, we repeated the belief update from 2015 to 2085, performing random draws at every annual time step, a total of 200 times (or 14000 annual draws in total). Additional repetitions $>200$ were not found to change our results significantly. The Monte Carlo procedure was coded in Matlab, and the run time for a single experiment was less than a minute.

\section{Climate Scenarios}

To represent different possible climate realizations we use precipitation and (near surface air) temperature output from model combinations in the COordinated Regional climate Downscaling EXperiment (CORDEX) database (Nikulin et al. 2012). In CORDEX, output from a substantial number of 
regional climate models (RCMs) forced on the boundaries of their model domains by global climate models or earth system models (for simplicity here referred to jointly as GCMs), delivered by numerous climate research institutes, are available across 14 different domains, which cover most regions of the world. To select three members representing different climate realizations, we assessed differences in model performance in terms of absolute and residual values, interannual variability, year-to-year amplitudes and projected future trajectories from a subset of the available $\mathrm{RCMs}$ over the African model domain, covering the entire continent. This resulted in data from the seven model combinations shown in table 1. Climate data for both the available historical period (1951-2005) and the projected future (2006-2100) were used. Annual mean temperature and precipitation anomalies were calculated using a reference period of 19792005. Both the (Representative Concentration Pathways) RCP4.5 and RCP8.5 trajectories (IPCC 2013) were considered in order to span a wider range of climate realizations and include scenarios of both intermediate as well as high future greenhouse gas emissions. The gridded data were extracted on a yearly basis and processed into a spatial mean for Ghana based on grid cells from the CORDEX domain in the latitude-longitude range of $5.7^{\circ} \mathrm{N}$ to $11.0^{\circ} \mathrm{N}$ and $2.6^{\circ} \mathrm{W}$ to $0.4^{\circ} \mathrm{E}$ respectively.

\begin{tabular}{|l|l|l|l|l|}
\hline No. & $\begin{array}{l}\text { GCM/RCM model } \\
\text { name }\end{array}$ & Abbreviated name & Comments & $\begin{array}{l}\text { Latest RCM } \\
\text { publication }\end{array}$ \\
\hline 1 & MPI-ESM - CCLM4 & MPI-CCLM & $\begin{array}{l}\text { C3 (RCP8.5) } \\
\text { High T, Low P }\end{array}$ & Baldauf et al. (2011) \\
\hline 2 & CNRM-CM5 - CCLM4 & CNRM-CCLM & As above \\
\hline 3 & MPI-ESM - CRCM5 & CRCM & $\begin{array}{l}\text { Not available for } \\
\text { RCP8.5 }\end{array}$ & Zadra et al. (2008) \\
\hline 4 & $\begin{array}{l}\text { EC-EARTH - } \\
\text { HIRHAM5 }\end{array}$ & HIRHAM & $\begin{array}{l}\text { C2 (RCP8.5) } \\
\text { Moderate T, High } \\
\text { P }\end{array}$ & $\begin{array}{l}\text { Christensen et al. } \\
\text { (2006) }\end{array}$ \\
\hline 5 & $\begin{array}{l}\text { EC-EARTH - } \\
\text { RACMO22 }\end{array}$ & RACMO & $\begin{array}{l}\text { C1 (RCP4.5) } \\
\text { Moderate T, P }\end{array}$ & Berg et al. 2013 \\
\hline 6 & $\begin{array}{l}\text { EC-EARTH - RCA4 } \\
\text { (2008) }\end{array}$ & RCA & Jacob et al. (2012) \\
\hline 7 & $\begin{array}{l}\text { EC-EARTH - } \\
\text { REMO2009 }\end{array}$ & REMO & & \\
\hline
\end{tabular}

Table 1. GCM/RCM model combinations assessed for the study and denotation of climate scenarios used in the decision-making model. C1 represents a moderate climate scenario, closest to present day conditions. $\mathrm{C} 2$ is cooler than the ensemble mean and represents a wet climate development. $\mathrm{C} 3$ is the warmest and driest projection of the ensemble. 
To assess also the sub-annual scales, the climate data were further analysed for changes in monthly values (not shown) as opposed to the annual means. A very limited agreement between the models was seen except for temperature in the RCP8.5 scenario where the temperature increase (as seen in annual values for figures 1 and 2) is generally stronger in the months November-June as opposed to July-October.

In the historical period annual mean temperatures generally increase from approx. $25^{\circ} \mathrm{C}$ around 1950 to approx. $25.5^{\circ} \mathrm{C}$ around 2005 (figure 1). Here the CRCM and RACMO models however differ with absolute values of approx. $24^{\circ} \mathrm{C}$ and $23^{\circ} \mathrm{C}$ increasing to approx. $25^{\circ} \mathrm{C}$ and $23.5^{\circ} \mathrm{C}$, indicating systematic biases from the ensemble mean of a different order of magnitude than the other models. For the RCP4.5 scenario average values increase steadily reaching approx. $27^{\circ} \mathrm{C}$ around 2070 and then slow down to reach approx. $27.5^{\circ} \mathrm{C}$ around 2100 . The CRCM and RACMO models exhibit the same systematic biases for the RCP4.5 scenario as in the historical period, showing lower values reaching approx. $26.5^{\circ} \mathrm{C}$ and $25^{\circ} \mathrm{C}$ in 2100 and with CRCM even showing a slight decrease in 2070-2100. For the RCP8.5 scenario, mean annual temperatures of approx. $30^{\circ} \mathrm{C}$ are seen by 2100 within the range of $29-31^{\circ} \mathrm{C}$ except for RACMO reaching approx. $27^{\circ} \mathrm{C}$. For both RCP scenarios, the largest amplitudes of interannual variations are found for the MPI-CCLM model.
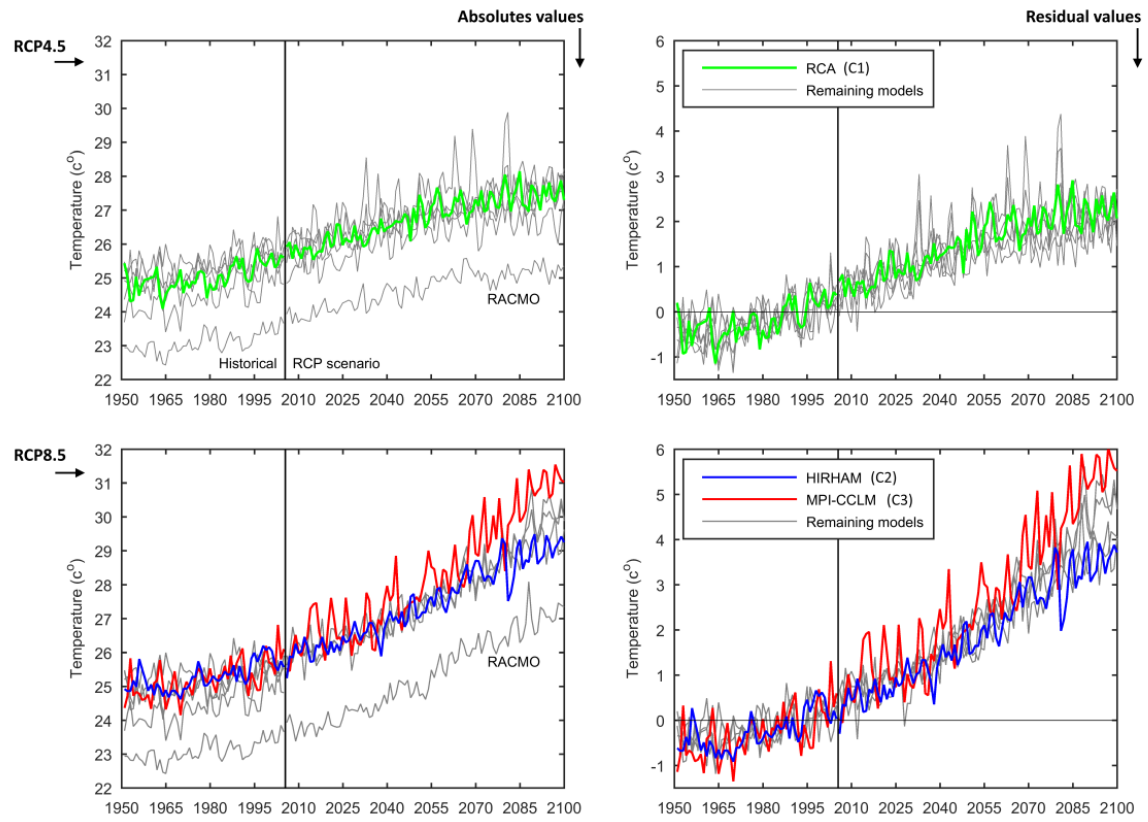

Figure 1: Temperature output (absolute and residual) over Ghana extracted from the CORDEX database as used to force the decision-making model. Output from the available historical period (1951-2005) and the RCP periods used (RCP4.5 and RCP8.5) are shown (2006-2100). The three scenarios used (C1-C3) are highlighted in colours. 
The precipitation data show a general spread in longer-term means between the models. In the 1951-2005 historical period, the inter-model spread varies between $990-1630 \mathrm{~mm} /$ year and averages $1310 \mathrm{~mm} /$ year (figure 2). For the RCP4.5 scenario (2006-2100) corresponding values are coinciding with the historical period (1000-1630 and $1330 \mathrm{~mm} /$ year), whereas the RCP8.5 scenario show a small decrease with values of 9501490 and $1290 \mathrm{~mm} /$ year. No data was available for the CRCM model (table 1) for RCP8.5, which proved to be the wettest model for RCP4.5. For this reason, the CRCM model results were excluded from calculations of the average model statistics for the historical and RCP8.5 analyses respectively (figures 1 and 2). For both RCP scenarios the ensemble mean statistics comprise diverging inter model patterns as some of the models show overall increases and vice versa. This is exemplified e.g. by HIRHAM and MPI-CCLM models exhibiting opposing slopes of 4.4 and $-3.1 \mathrm{~mm} /$ year in 2006-2100 for the RCP8.5 simulations (figure 2). In addition, a noticeable interannual variation is seen exemplified by a minimum-to-maximum difference in the historical period between 420 and $790 \mathrm{~mm}$. The analysis of temperature and precipitation for the future period of 2006-2100 correspond with Deque et al. (2016), indicating similarly that the annual mean temperature in Ghana is expected to increase by between 2 and $6^{\circ} \mathrm{C}$ and that change in rainfall is, on average, still uncertain but in any case modest compared to the interannual variability.
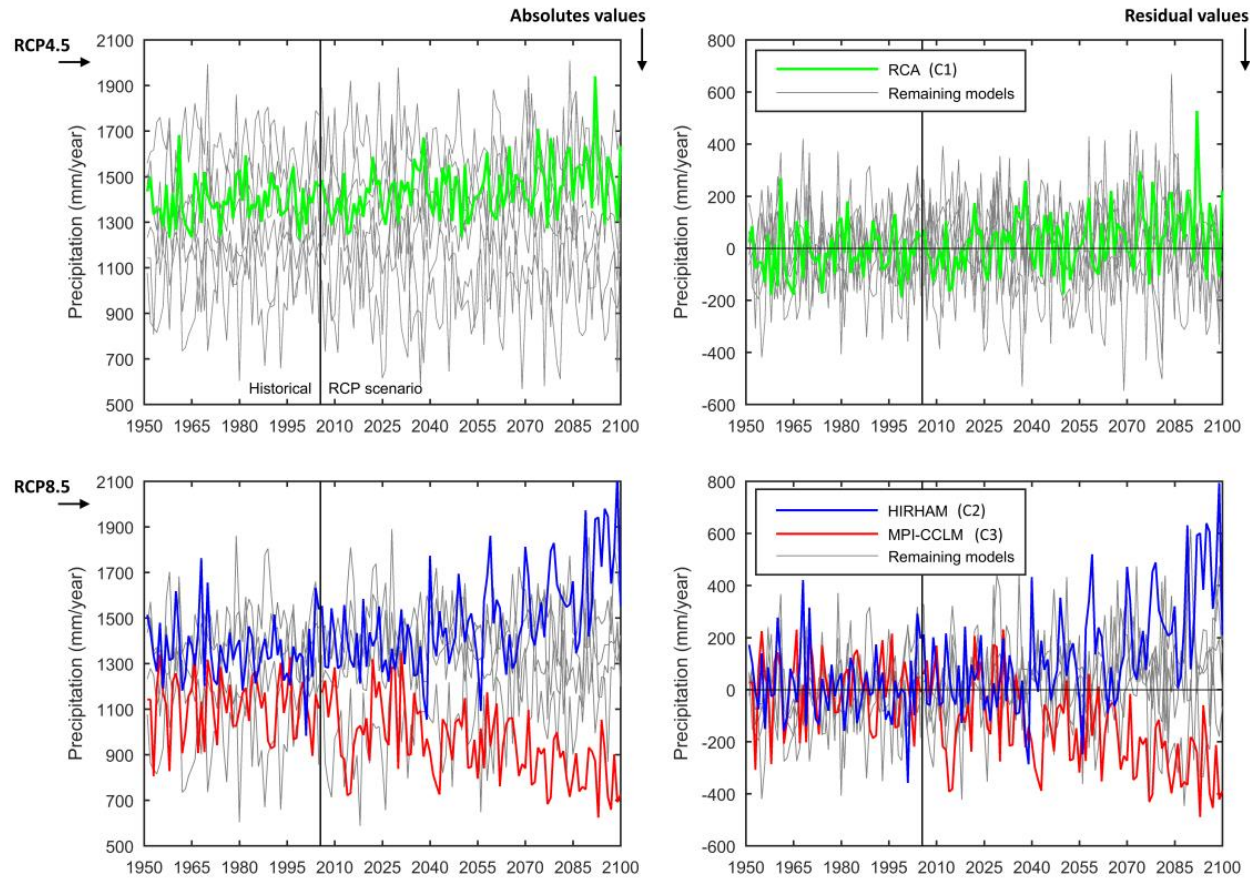

Figure 2: Same as for figure 1, for precipitation output. 
Lastly, we also analysed the Pearson linear correlation between temperature and precipitation for each of the five-year periods based on 30-year running time slices as discussed above (results not shown). Here the seven models were found to behave quite differently, with one model (MPI-CCLM) showing a strong and increasingly negative correlation towards the end of the century, whereas other models showed positive correlations or no trend at all. Based on the combined results we finally selected three climate projections to be used for the further analyses, reflecting the full span of possible climatic outcomes. As a low GHG emission and low impact scenario, we selected projections of the RCP4.5 scenario produced by the RCA RCM (hereafter entitled C1) to constitute a 'baseline' climate of minimal change. The second scenario (HIRHAM, RCP8.5 - entitled C2) was chosen due to being wetter than most, representing a temperature increase in the lower range of the models included here, and exhibiting a slightly positive correlation between temperature-precipitation. Conversely, the third scenario (MPI-CCLM, RCP8.5 - entitled C3) was selected for being the driest, having the highest temperature increase by the end of the century and a strong negative temperature and precipitation correlation.

\section{Agricultural Systems}

We assume for simplicity that the farmer's principal objective is to maximise the net revenue of personal agricultural activities. To this purpose, we adopt the economic model developed by Kurukulasuriya et al. (2006) and apply this to Ghana. In this cross-sectional approach the relationships between climate and net revenues from three different agricultural systems: dry crops, irrigated crops and livestock are studied using a standard Ricardian model formulation for each agricultural system. Based on an ordinary least squares regression and using the results of more than 9,000 farm surveys conducted in 11 different countries in Africa (including information on water flows, soil types and economic variables), the marginal climate impacts on net farm revenues per farm (in USD) as estimated by Kurukulasuriya et al. (2006) are reproduced in table 2 .

The marginal effect of changes in precipitation specified by the coefficients in table 2 corresponds to an increase in the annual mean precipitation of 1 $\mathrm{mm}$ (calculated from monthly means). Similarly, the marginal effect of changes in temperature corresponds to an increase in the annual mean temperature of $1^{\circ} \mathrm{C}$. The baselines for these estimates were set by time series of climate observations spanning 1988-2003 (temperature) and 19772000 (precipitation). The numbers in parenthesis further indicate the upper and lower bounds, respectively, of the $95 \%$ confidence intervals related to 
the estimated coefficients (table 2). In the following, these upper and lower bounds will be referred to as the 'minimum' and 'maximum' coefficients respectively, and they will be used to explore the uncertainty related to the economic model. Similarly, the coefficients corresponding to the results of the ordinary least squares regression is referred to as the 'mean coefficients'. For more details about the model, a detailed description is provided in Kurukulasuriya et al. (2006).

\begin{tabular}{|l|r|r|r|}
\hline $\begin{array}{l}\text { Marginal } \\
\text { impact }\end{array}$ & Dryland crop & Irrigated crop & Livestock \\
\hline OLS & & & \\
\hline Temperature & $-239^{* * *}(-335,-142)$ & $3005(-2040,8048)$ & $-379(-775,17)$ \\
\hline Precipitation & $15^{* * *}(5.1,25)$ & $301.3(-896.6,1499.3)$ & $19.9 * *(0.3,39.5)$ \\
\hline
\end{tabular}

Table 2. Marginal climate impacts on net revenue per farm (US Dollars/USD) based on data presented by Kurukulasuriya et al. (2006). Ordinary Least Square (OLS) numbers in parentheses indicate the $95 \%$ confidence intervals. ${ }^{* *} p<0.05$, and ${ }^{* * *} p<0.01$.

The main advantage of the regression type model by Kurukulasuriya et al. (2006) is that the net revenues revealed by their analyses in a simple way reflects the benefits and costs of autonomous adaptation and coping strategies, such as the choice of sowing method and timing. This includes a variety of contributions and the introduction of substitute actions, which farmers have incorporated in order to adapt to the current climate viabilities. As a result, it is readily possible within the framework to simulate an irreversible decision, as autonomous adaptation is already included. Labour costs have not been included, since the shadow price of wages that farmers apply to their own time cannot easily be measured.

Conversely, it is also evident that the Ricardian model has its obvious deficiencies. Given that the empirical data spans 11 countries across the entire African continent the coefficients in table 2 are found to vary considerably, which is perhaps most evident in the case of irrigated farming. Considering this uncertainty the results of modelling net farm revenues will similarly be associated with large spreads depending on whether the minimum coefficient (which is negative in the case of irrigated farming) or, say, the mean coefficient (which is positive in the case of irrigated farming) is used. If only the mean coefficients are considered, it is furthermore clear that the model is strongly biased towards irrigated farming, which Kurukulasuriya et al. (2006) attributes to an overrepresentation of data on irrigated farming from Egypt; whereas in Ghana existing crops are mainly rain fed. 
Since this study mainly addresses the demonstration of how farmers' beliefs can influence management and not quantitative impact assessments, we have adopted the model by Kurukulasuriya et al. (2006) as it is. However, we will explore the span of possible outcomes by considering not only the mean coefficients but also their minimum and maximum values. We hereby also emphasize that for more quantitative and local studies the authors would endorse modelling approaches that are more realistic.

In the following sections, we show the results of simulating optimal decision-making using the described Bayesian methodology while evaluating the mean annual net revenues related to agricultural activities every five years starting in 2020 and ending in 2085. The latter is discussed in the context of choosing between the three types of agricultural systems. For this purpose, we use the following assumptions: The farmer makes rational decisions; the farmer is not risk adverse; the farmer bases decisions on agricultural systems on net revenue; the farmer has access to information about agricultural systems on which decisions are based in each step of the framework; the farmer can only use one agricultural system at a time.

\section{Results}

Presented here are the simulated results using our Bayesian formulation. The updating of the farmer's beliefs towards the realised climate trajectory over time is shown in figure 3, as described in equations 1-4 and in Yousefpour et al. (2015). The updated beliefs are shown for four combinations of initial conditions, i.e. corresponding to a farmer's initial bias (either equally distributed or with an $80 \% / 10 \% / 10 \%$ belief towards a specific realised climate), and the three climate scenarios. The figure shows that irrespective of the simulation setup and the initial situation the farmer's beliefs, all scenario runs eventually converge on the realised climate, albeit the convergence time varies from within a few years to the end of the century and with diverging pathways. The duration until convergence is found primarily to be a function of the realised climate with shorter convergence times from $\mathrm{C} 1$ through to $\mathrm{C} 3$. The observed convergence times are highly correlated with the (combined) climate signal seen in the temperature and precipitation data (figures 1 and 2 respectively). Especially the lack of a clear precipitation signal in $\mathrm{C} 1$ is likely to temporally restrain the certainty in climate scenario belief whereas the combined strong decrease in precipitation and strong increase in temperature in C3 leads to a swift convergence here. Interestingly, the time until convergence is found to be shortened by $5-10$ years when the farmer's initial belief bias $(80 \%)$ is 
directed towards a specific climate realization. Since the turn-around time for real agriculture systems is likely to be in the same order of magnitude, this implies that for real-life decision-making such a shortening could be incredible consequential, and clearly underlines the importance of building confidence in climate projections with farmers.
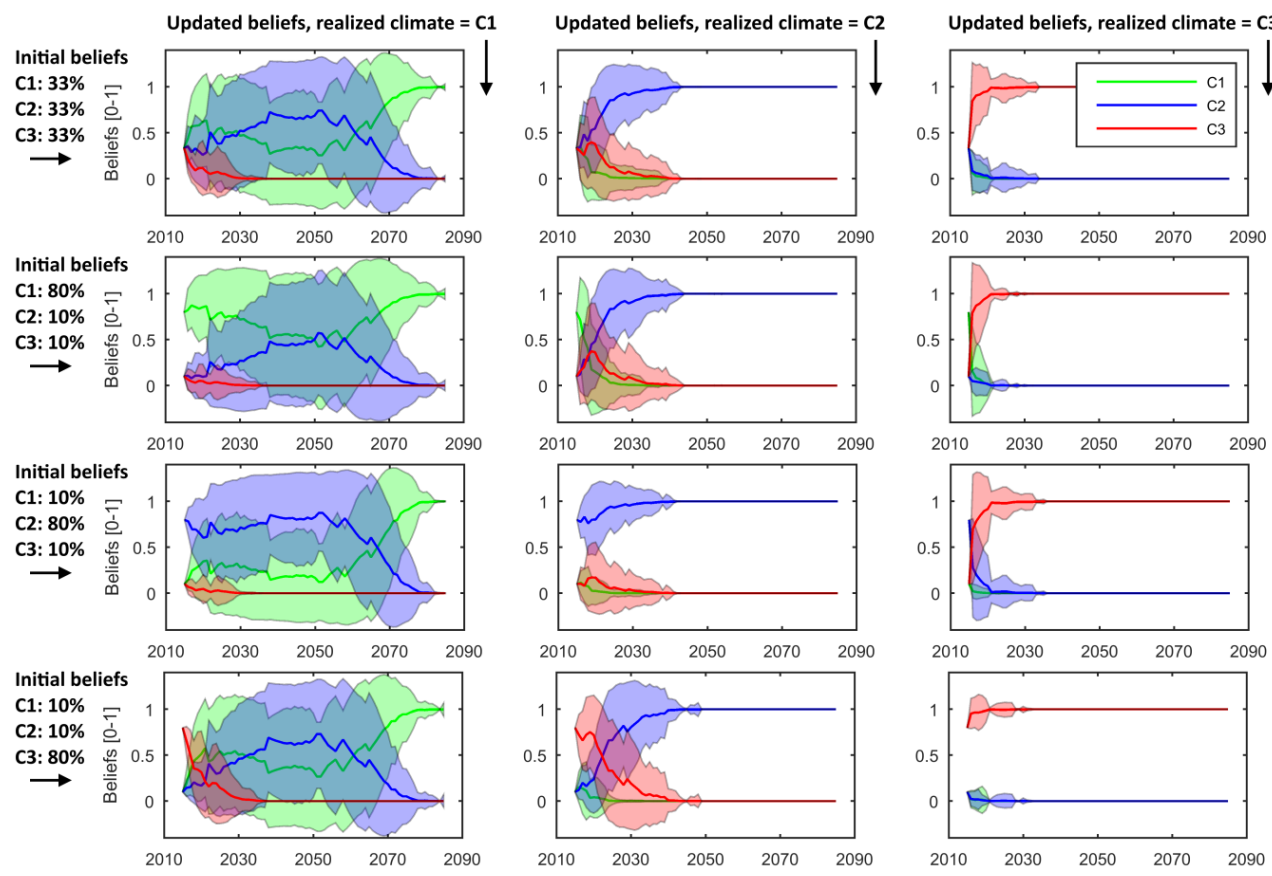

Figure 3. Update of belief during the study period dependent on initial belief and realized climate.

The resulting net revenues based on each of the climate scenarios, C1-C3, and agricultural systems, dryland, irrigated and livestock, are depicted in figure 4. From the figure, three main points are evident: I) between each agricultural system, high general variations in net revenues are seen with values in both the profitable and non-profitable (negative) range. Specifically, dryland crops in C3 (dry and warm) and livestock in all scenarios (C1-C3) turns non-profitable for results using the mean coefficients to project the revenues. Assessing the entire span of net revenues using minimum and maximum coefficients significantly increases the spread of possible net revenues for each agricultural system and especially for irrigated agriculture (notice the varying $y$-axis limits in figure 4) which is also evident when assessing the coefficients in table 2. II) The climate scenario, C1-C3, has a distinct effect on the resulting trajectory for net revenue e.g. with an incisive negative development for dryland and livestock systems 
under C3. III) Finally, short-term climate variability affects the net revenues with positive-to-negative year-to-year net revenue variations.


Figure 4. Calculated net revenues during the study period dependent on agricultural system practice and realized climate. All results are plotted as minimum and maximum coefficients (95\% confidence: coloured area - see table 2) around the mean net revenue functions (Kurukulasuriya et al. (2006). For easier comparison, results are sorted for both agricultural system (left column) and realized climate (right column). For the realized climate, the y-axis limits are specified to enable comparisons between dryland and livestock systems as the irrigated practice generates significantly higher net revenues. All realizations are with equal initial beliefs between agricultural systems (33\%).

The resulting net revenues (USD/farm) and choices of agricultural systems (1-3) as a function of time (2020-2085), based on the maximization of the former, is shown in figure 5 . Results are given for combinations of the four distributions of initial beliefs, the three realised climates and using the mean and minimum coefficients of the economic model. From figure 5 , we clearly find that employing irrigated agriculture is the optimal agricultural system regardless of the realised climate scenario when using mean coefficients. The net revenue function following the development of the climate trajectory, assuming $\mathrm{C} 1$ is the realised climate scenario, shows large variations for the different initial beliefs of the farmer. The distance between the curves here represent the possible range of net revenues on which the farmer must make decisions. When using the minimum coefficients, dryland 
agriculture is preferred over the other agricultural systems in 2025 and from 2035 and onwards for C1 and C2, whereas for C3 irrigated agriculture still maximizes the net revenue (converged from 2040 and onwards). For all combinations of realised climate and coefficients, the influence of the farmer's initial beliefs is found to diminish or completely disappear within, most often, the first 5-10 simulation years. Climate scenario $\mathrm{C} 1$, using mean coefficients, is an exception. This is caused by the corresponding substantial shifts in the farmer's preference for $\mathrm{C} 1$ throughout the analysis period, as evident in figure 3.
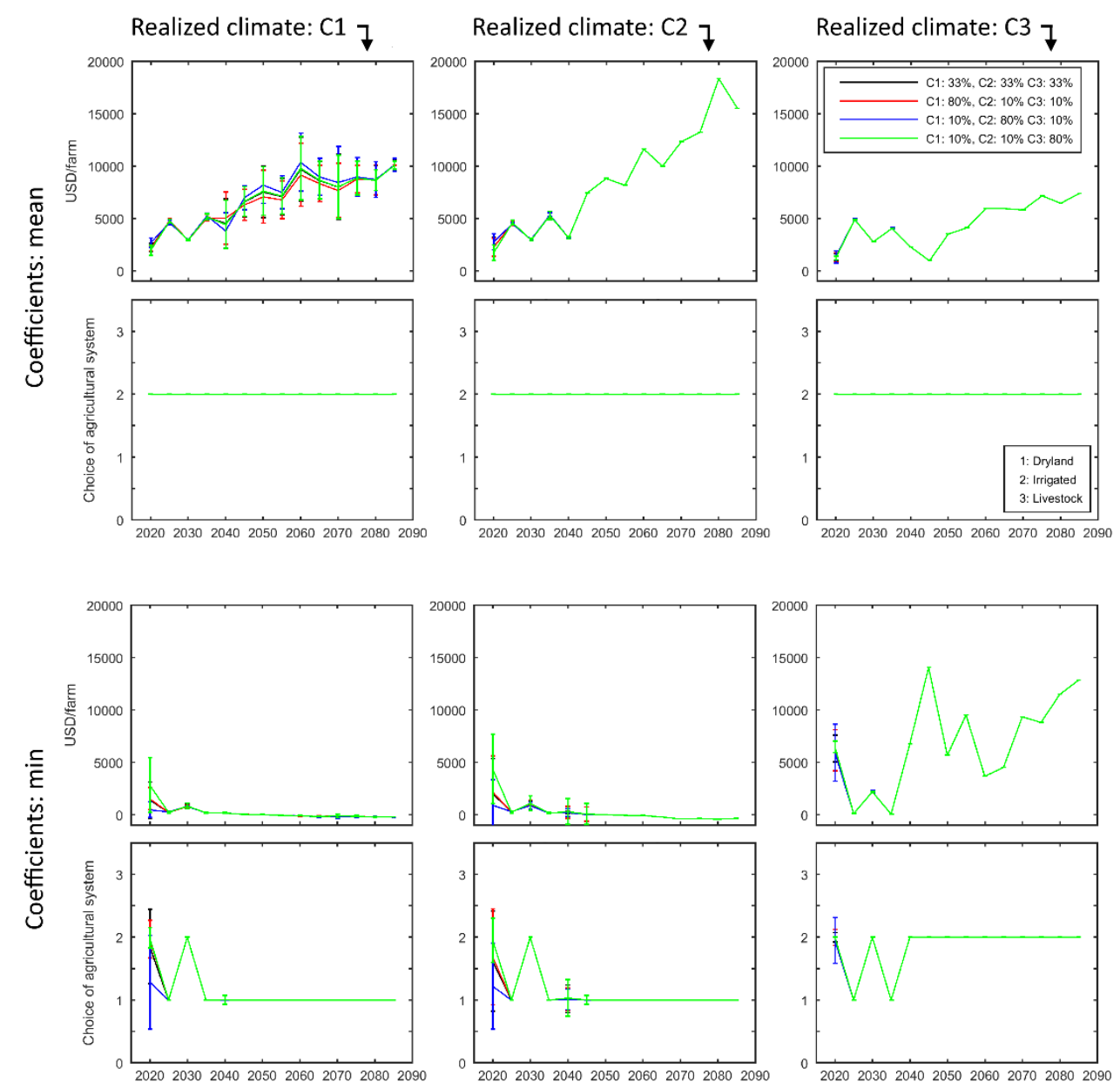

Figure 5. Choice of agricultural system (1-3) based on net revenue maximization USD/farm) dependent on the realized climate in the three climate scenarios (C1-C3; temperature and precipitation) and the farmer's initial belief. Results are presented dependent on the use of mean or minimum ( $95 \%$ confidence) net revenue coefficients (table 2) as discussed above (as in Kurukulasuriya et al. (2006)). 


\section{Concluding Discussion}

This study explores a Bayesian framework for simulating the consequences of decision-making under the uncertainty of climate change. Adapting the methodology originally introduced by Yousefpour et al. $(2014,2015)$ we simulate how an adaptive decision-maker can change behaviour in response to progressive observations of climate change impacts, the consequences of decisions made, and finally the potential for making 'optimal' decisions on adaptation (type and timing). Similar work within this field includes thematic areas such as relocation of species (McDonald-Madden et al. 2011), sea level rise (Martin et al. 2011) and agricultural adaptation (Chhetri et al. 2010).

The aim of the paper is to add to the discussion on how numerical simulations and in particular Bayesian updating can contribute to the development of adaptation to climate change, and how decision-makers can cope with the uncertainty of climate change. The following discussion will therefore focus on the Bayesian updating framework, its relevance and opportunities for improvement. The results regarding which agricultural system to choose, when to implement it and the possible net revenues involved will only be briefly touched upon, as the data and net revenue functions are not suited for this purpose; cf. the above section on Agricultural Systems.

Arguably, numerical approaches can help to bridge the gap between the evolving climate change and management decisions facing farmers. The latter is often based on combinations of parameters, e.g. sociological, economic and ecological. For simplicity, this paper solely considers the farmer's observations of precipitation and temperature and updates the weight of beliefs towards specific climate projections thereupon. This is followed by observations of net revenues from different agriculture systems based on these beliefs, and finally a decision is simulated based on the observations. Despite these limitations, we argue that the approach presented here is still useful in that it frames the different options available to farmers facing climate change, including the consequences of initial belief biases. As mentioned above the latter is potentially quite important in real life, since the length of a convergence period of 5-10 year can be quite substantial in the case of real agricultural systems.

Using the Bayesian formulation, we demonstrate that it is possible to simulate future choices of the farmer, to contradict original beliefs and to highlight the consequences of having made a wrong choice. A key finding in this context is that irrigated crops, independently of the realised climate development, are found to be the preferred choice of agricultural system regardless of climate scenario as seen from the upward-sloping curve for net 
revenues (figure 3 ). The choice of irrigated crops however, may be too optimistic and unrealistic, as the implementation of irrigated crops will require making considerable investments (depending on the way irrigation is established and carried out). As discussed by Chhetri et al. (2010) irrigated crops may thus be unavailable to many farmers, as this agricultural system entails more intensive management in addition to high costs of implementation. Then there is the fundamental issue of uncertainty related to the estimates of revenues from agricultural systems. In the model developed by Kurukulasuriya et al. (2006) the mean coefficients used (table 2) are biased towards, countries (e.g. Egypt) where irrigation water is presently available and therefore already implemented into the agricultural system. Therefore, the results based on using the minimum coefficients (corresponding to the lower bounds of the $95 \%$ confidence interval), where the dryland agricultural system is seen to be preferred in case of two climate scenarios, is likely to be more realistic for this Ghanaian example. The right column in figure 4 illustrates how the competition between different agricultural systems develop through the three climate scenarios and over time. By applying the minimum coefficients (representing uncertainty of the economic estimates) in the economic model, assumed to be more realistic in the case of Ghana, it is possible to demonstrate how farmers can potentially change behaviour over time in response to new information, contradictory to original beliefs.

The lack of opportunities for implementing irrigated farming, as highlighted above, also has implications regarding the remaining two agricultural systems. Dryland crops are generally cultivated on the farmer's privately owned land, whereas it is normal in many locations to use common or public land for livestock grazing (Kurukulasuriya et al. 2006; Kassahun and Jacobsen 2015). Consequently, there is no linear relationship between a farmer's income from livestock and the amount of land owned or with the right to cultivate. The choice between livestock and dryland crops is thus more a matter of where to make an effort in terms of required investments (e.g. seeds, animals) and labour. In addition, the term livestock covers a huge range of animals, and thus it should be taken into consideration that small livestock such as goats are more heat tolerant than cattle. These issues have, to some extent, already been incorporated into the modelled net revenues for livestock, as the data from Kurukulasuriya et al. (2006) include a variety of contributions and alternative actions, which farmers have introduced in order to adapt to current climate viabilities. The discussion concerning where to make the effort further leads to a discussion of the labour costs, since the cost of household labour has not been included into the functions used for estimating the net revenues of the different agricultural systems. The results of Kurukulasuriya et al. (2006) indicate that growing crops is 
more management intensive than keeping livestock. This can be assumed since a large household typically claims higher revenues from crops and lower revenues from livestock than a smaller household. The width of the confidence intervals for the coefficients related to irrigated farming and applied in figure 4 clearly shows that the net revenues generated from irrigated farming are more sensitive to climate change variabilities than dryland crops. Implicitly, this could imply that the farmer is likely to be more willing to update individual beliefs if observed changes concern precipitation rather than temperature, since precipitation is found to have the greater influence on growth. Evidently, this will be entirely contingent on the form of the economic model. Conversely, the huge observed inter-annual variability in precipitation can lead the decision-maker to erroneously update beliefs. This is for example part of the explanation why we see the frequent simulated changes between agricultural systems in figure 5 in the early years until year 2040 (when using the minimum coefficients in the economic model). The increasing precipitation patterns for $\mathrm{C} 2$ from approx. 2040 and onwards causes the farmer to choose dryland crops from this point in time. Conversely, for the C3 scenario the observed decrease in precipitation causes the opposite trend - towards a choice of irrigated crops. An additional factor driving this behaviour is the stronger temperature increase for C3 as compared to C2 (figure 1).

In this study, we simulate a farmer's ability to adapt proactively by considering a choice of three agricultural systems every five years. This is of course not realistic: In many cases a change of agricultural system represents at some level an irreversible decision (as also discussed by Chhetri et al. 2010), compared to more untenable coping strategies for building resilience to climate change such as reduced consumption, cash savings or increase in debt. Furthermore, one should not forget that the setting is highly dynamic, and as highlighted above, the line between proactive and reactive behaviour can be blurred, meaning that what is optimal today may not be optimal in the years to come. In addition, there is the matter concerning barriers to climate change adaptation: It can be difficult for the individual farmer to sell crops if there is no market; this is a question of supply and demand and having access to a market (e.g. Antwi-Agyei, Dougill and Stringer 2015).

Finally, it may be relevant to mention how most farmers will in fact choose to combine the three suggested agricultural systems. This is documented for example in the surveys used by Kurukulasuriya et al. (2006), who report that farmers, if possible and locally conditioned, often choose combinations of these three main agricultural systems to optimise their net revenues and minimise their risks. This option has not been considered in the current decision-making framework, which for the sake of demonstration employs a 
range of simplifying economic assumptions and similarly a basic regression model to connect estimates of net revenues with changing climatic conditions. Contrastingly, the present set of climate scenarios used in this study were carefully selected based on a thorough analysis of the CORDEX ensemble of state-of-the-art RCM projections for Africa, representing three different and equally plausible future climates in Ghana. The detailed climate analysis for selecting the three representative ensemble members considered the diverging trajectories of both temperature and precipitation for different ensemble members as well as the associated correlations and inter-annual variabilities. The choice to consider only three climate realisations was motivated largely to stay consistent with the work of Yousefpour et al. $(2014,2015)$. Thus, for some applications it could have been relevant to add more realisations to the analysis. In a similar way, the 'true' climate development could have been represented by a fourth climate projection to introduce a sort of cross-validation and to illustrate the role of a climate modelling bias in the decision-making framework.

The Bayesian approach used here to simulate agricultural adaptation to climate change presents a general framework, which may be applicable for modelling decision-making and path dependencies affected by different sources of uncertainty. As such, the present case study can be considered as a first step in developing a comprehensive theoretical approach for studying and managing climate change adaptation under non-stationary conditions, related to both proactive and reactive responses. Other settings where this approach could be applied include the implementation of policies, regional decision-support or support from donors and NGO's, representing activities that are often very time consuming to implement and may incur irreversible decisions with substantial resulting consequences.

In terms of advancing the present simulations, most importantly, we recognise the need to move on from the current simple representation of agricultural systems at the farm-scale to a more complex representation, including higher levels of aggregation, for example to capture issues related to scarcity of water resources which is better addressed at the village or regional scale. Using the current formulation, we thus derive a clear preference for irrigated farming in Ghana, which is likely to be, at least, somewhat unrealistic. In practice, it might simply not be possible for all farmers in a region to irrigate their crops. Perspectives of further developing the Bayesian methodology presented in this paper will include the possibility of merging individual decision-making with available natural resources, based on a more empirical knowledge of farmer's climate change adaptation choices, or coping in the case of substantial unexpected shocks. In a wider perspective, it would also be interesting to explore whether the Bayesian 
framework could contribute to revealing and identifying opportunities for adaptation and mitigation of climate changes and - if possible - how it may contribute to jointly optimising farmers' resilience to climate change and promote increased sustainable development.

\section{Acknowledgements}

The authors would like to acknowledge Professor Jette Bredahl Jacobsen, University of Copenhagen, and Head of Programme Dr. Anne Olhoff and colleagues at the UNEP DTU Partnership for providing constructive criticism and Yousefpour et al. $(2014,2015)$ for inspiring this work. Part of the project was carried out under the eSACP project supported by the Nordic Council of Ministers under the Global e-Science initiative.

\section{References}

- Antwi-Agyei P, Dougill AJ, Stringer LC (2015) Barriers to climate change adaptation: evidence from northeast Ghana in the context of a systematic literature review. Climate and Development 7:297-309. doi: 10.1080/17565529.2014.951013

- Antwi-Agyei P, Fraser EDG, Dougill AJ, et al (2012) Mapping the vulnerability of crop production to drought in Ghana using rainfall, yield and socioeconomic data. Applied Geography 32:324-334. doi: 10.1016/j.apgeog.2011.06.010

- Antwi-Agyei P, Stringer LC, Dougill AJ (2014) Livelihood adaptations to climate variability: insights from farming households in Ghana. Regional Environmental Change 14:1615-1626. doi: 10.1007/s10113-014-0597-9

- Arrow KJ, Fisher AC (1974) Environmental Preservation, Uncertainty and Irreversibility. Quarterly Journal of Economics 88:312-319.

- Baldauf M, Seifert A, Förstner J, et al (2011) Operational Convective-Scale Numerical Weather Prediction with the COSMO Model: Description and Sensitivities. Monthly Weather Review 139:3887-3905. doi: 10.1175/MWR-D10-05013.1

- Bayes T, Price M (1763) An Essay towards Solving a Problem in the Doctrine of Chances. Philosophical Transactions of the Royal Society of London. 53:370418.

- Benhin JKA (2008) South African crop farming and climate change: An economic assessment of impacts. Global Environmental Change 18:666-678. doi: 10.1016/j.gloenvcha.2008.06.003

- Berg P, Döscher R, Koenigk T (2013) Impacts of using spectral nudging on regional climate model RCA4 simulations of the Arctic. Geoscientific Model Development Discussions 6:495-520. doi: 10.5194/gmdd-6-495-2013 
- $\quad$ Boko M, Niang I, Nyong A, et al (2007) Africa. In: Climate Change 2007: Impacts, Adaptation and Vulnerability. Contribution of Working Group II to the Fourth Assessment Report of the Intergovernmental Panel on Climate Change. M. L. Parry, O. F. Canziani, J. P. Palutikof, P. J. van der Linden and C. E. Hanson (Eds.). Cambridge University Press, Cambridge, UK, pp. 433-467.

- Chhetri NB, Easterling WE, Terando A, Mearns L (2010) Modeling Path Dependence in Agricultural Adaptation to Climate Variability and Change. Annals of the Association of American Geographers 100: 894-907.

- Christensen OB, Drews M, Hesselbjerg JC, et al (2007) The HIRHAM Regional Climate Model. Version 5 (beta). Danish Climate Centre, Danish Meteorological Institute

- Budescu DV, Broomell S, Por H-H (2009) Improving communication of uncertainty in the reports of the Intergovernmental Panel on Climate Change. Psychological science 20:299-308.

- Challinor AJ, Watson J, Lobell DB, et al (2014) A meta-analysis of crop yield under climate change and adaptation. Nature Climate Change 4:287-291. doi: 10.1038/nclimate2153

- Das Gupta M (2014) Population, Poverty, and Climate Change. World Bank Research Observer 29, No. 1: 83-108.

- Deser C, Phillips A, Bourdette V, Teng H (2012) Uncertainty in climate change projections: the role of internal variability. Clim Dyn 38:527-546. doi: 10.1007/s00382-010-0977-x

- Déqué M, Calmanti S, Christensen OB, et al (2016) A multi-model climate response over tropical Africa at $+2^{\circ} \mathrm{C}$. Climate Services. doi: 10.1016/j.cliser.2016.06.002

- Field CB, Barros VR, Mastrandrea MD, et al (2014) Summary for policymakers. Climate change 2014: impacts, adaptation, and vulnerability Part A: global and sectoral aspects Contribution of Working Group II to the Fifth Assessment Report of the Intergovernmental Panel on Climate Change 1-32.

- Frankhauser S, Smith JB, Tol RSJ (1999) Weathering climate change: some simple rules to guide adaptation decisions. Ecological Economics 30(1):67-78.

- Halsnæs K, Shukla P, Ahuja D, et al (2007) Framing issues. In: Climate Change 2007: Mitigation. Contribution of Working Group III to the Fourth Assessment Report of the Intergovernmental Panel on Climate Change. Metz, B., Davidson, O. R., Bosch, P. R., Dave, R. and Meyer, L. A. (Eds.). Cambridge University Press, Cambridge, UK and New York, NY, USA, pp. 117-167.

- Hawkins E, Sutton R (2011) The potential to narrow uncertainty in projections of regional precipitation change. Climate Dynamics 37:407-418. doi: 10.1007/s00382-010-0810-6

- IPCC (2013) Climate Change 2013: The Physical Science Basis. Contribution of Working Group I to the Fifth Assessment Report of the Intergovernmental Panel on Climate Change. Stocker TF, Qin D, Plattner G-K, et al (Eds.). Cambridge University Press, Cambridge, UK and New York, NY, USA. 
- IPCC (2014) Summary for policymakers. In: Climate Change 2014: Impacts, Adaptation, and Vulnerability. Part A: Global and Sectoral Aspects.

Contribution of Working Group II to the Fifth Assessment Report of the Intergovernmental Panel on Climate Change. Field CB, Barros VR, Dokken DJ, et al (Eds.). Cambridge University Press, Cambridge, United Kingdom and New York, NY, USA.

- Jacob D, Elizalde A, Haensler A, et al (2012) Assessing the Transferability of the Regional Climate Model REMO to Different COordinated Regional Climate Downscaling EXperiment (CORDEX) Regions. Atmosphere 3:181-199. doi: 10.3390/atmos3010181

- Kassahun HT, Jacobsen JB (2015) Economic and institutional incentives for managing the Ethiopian highlands of the Upper Blue Nile Basin: A latent class analysis. Land Use Policy 44:76-89. doi: 10.1016/j.landusepol.2014.11.017

- Klibanoff P, Marinacci M, Mukerji S (2005) A smooth model of decision making under ambiguity. Econometrica 73:1849-1892.

- Kurukulasuriya P (2006) Will African Agriculture Survive Climate Change? The World Bank Economic Review 20:367-388. doi: 10.1093/wber/lhl004

- Larsen MAD, Thejll P, Christensen JH, et al (2013) On the role of domain size and resolution in the simulations with the HIRHAM region climate model. Climate Dynamics 40:2903-2918. doi: 10.1007/s00382-012-1513-y

- Lecocq F, Shalizi Z (2007) Balancing expenditures on mitigation of and adaptation to climate change: an exploration of issues relevant to developing countries.

- Martin J, Fackler PL, Nichols JD et al. (2011) Structured decision making as a proactive approach to dealing with sea level rise in Florida. Climatic Change: 107, 185-202.

- McDonald-Madden E, Runge MC, Possingham HP, Martin TG (2011) Optimal timing for managed relocation of species faced with climate change. Nature Climate Change 1: 261-265.

- Nikulin G, Jones C, Giorgi F, et al (2012) Precipitation Climatology in an Ensemble of CORDEX-Africa Regional Climate Simulations. Journal of Climate 25:6057-6078. doi: 10.1175/JCLI-D-11-00375.1

- Oreskes N, Shrader-Frechette K, Belitz, K (1994) Verification, Validation, and Confirmation of Numerical Models in the Earth Sciences. Science 263:641646.

- Refsgaard JC, Madsen H, Andréassian V, et al (2014) A framework for testing the ability of models to project climate change and its impacts. Climatic Change 122:271-282. doi: 10.1007/s10584-013-0990-2

- Simal PD, Ortega ST (2011) Option and quasi-option value. An approach to deal with climate change effects in coastal areas. Oceans, 2011 IEEE - Spain, pp. 1-7. 
- Stern N (2006) The Economist of Climate Change: The Stern Review. Cambridge University Press, Cambridge, UK and New York, NY, USA.

- Stocker TF, Qin D, Plattner GK, et al (2013) IPCC, 2013: climate change 2013: the physical science basis. Contribution of working group I to the fifth assessment report of the intergovernmental panel on climate change.

- Tschakert P, Dietrich KA, others (2010) Anticipatory learning for climate change adaptation and resilience. Ecology and society 15:11.

- Van Meijgaard E, Van Ulft LH, Van de Berg WJ, et al (2008) The KNMI regional atmospheric climate model RACMO version 2.1.

- Vardas G, Xepapadeas A (2010) Model Uncertainty, Ambiguity and the Precautionary Principle: Implications for Biodiversity Management. Environmental and Resource Economics 45:379-404. doi: 10.1007/s10640009-9319-z

- Yip S, Ferro CAT, Stephenson DB, Hawkins E (2011) A Simple, Coherent Framework for Partitioning Uncertainty in Climate Predictions. Journal of Climate 24:4634-4643. doi: 10.1175/2011JCLI4085.1

- Yousefpour R, Didion M, Jacobsen JB, et al (2015) Modelling of adaptation to climate change and decision-makers behaviours for the Veluwe forest area in the Netherlands. Forest Policy and Economics 54:1-10. doi: 10.1016/j.forpol.2015.02.002

- Yousefpour R, Jacobsen JB, Meilby H, Thorsen BJ (2014) Knowledge update in adaptive management of forest resources under climate change: a Bayesian simulation approach. Annals of Forest Science 71:301-312. doi: 10.1007/s13595-013-0320-x

- Zadra A, Caya D, Côté J, et al (2008) The next Canadian regional climate model. Phys Can 64:75-83. 